\title{
Persuasion in Messages ${ }^{1}$
}

\author{
Laura Gorham, Ricky Telg, and Tracy Irani²
}

\section{Introduction}

The mass media use persuasion to influence how their audience - the general public - should think about or perceive certain topics. Specific contextual cues are added to media messages that persuade people to think one way or another about an issue and influence their actions. In this publication, you will learn the different ways that the mass media use persuasion and how persuasion encourages the audience to change their attitudes or behavior.

\section{Persuasion in the Mass Media}

Persuasion is an element of what we see, hear and read in the mass media. Advertisers and marketers want to persuade audience members to buy their products. Politicians want to persuade voters to support them. Policymakers and activists hope to persuade citizens to agree with their views on certain issues. One way they all do this is through a concept called framing.

Although journalists strive for objectivity, they often use media framing to organize stories and uncover meaning. The ways in which they describe what they report help to "frame" a story's content. Framing refers to the context of a message or the way in which a message is presented. Framing focuses on these related questions: What message is portrayed, and how is the message portrayed? Frames can be found in newspaper or magazine articles, TV stories, or even political speeches. Frames can be photographs, video, or the words of someone who is quoted in a newspaper or magazine article or heard on a television news story.

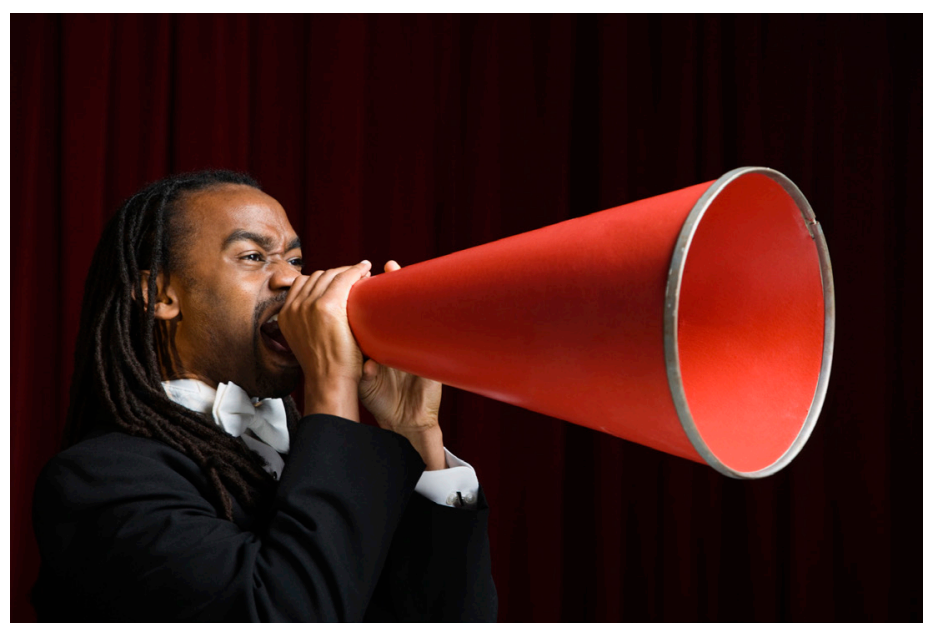

In essence, framing provides cues or the borders - like a picture frame - of what to consider when viewing, listening, or reading different media.

For example, the selection of given words can affect the consideration of information and the audience's reaction to it. Framing can significantly affect the perception of an issue and the evaluation of alternative options. The use of the word "Frankenfood" in a story about genetically modified food would be a frame that adds a negative element to the description. Photographs or video of leaking barrels of chemicals would be a negative frame for a story about how pesticides are applied to food crops. A positive frame would be a series of photographs in a newspaper showing $4-\mathrm{H}$ members participating in the local youth fair.

1. This document is AEC482 (formerly WC145), one of a series of the Agricultural Education and Communication Department, UF/IFAS Extension. Original publication date July 2013. Visit the EDIS website at http://edis.ifas.ufl.edu.

2. Laura Gorham, graduate student; Ricky Telg, professor; and Tracy Irani, professor, Agricultural Education and Communication Department, UF/IFAS Extension, Gainesville, FL 32611. 
Framing can be a valuable tool for communication professionals in advertising, marketing, and public relations. Ultimately, communicators want their product, service, event, or company "framed" in as positive a light as possible. Understanding framing helps media professionals describe their topics more favorably when they seek media coverage. For example, you probably would never see a revised product advertised as "old and stodgy." Most likely, the product would be framed as "new and improved" so that the product is viewed as positively as possible.

When framing a message ask yourself the following:

- What idea or proposal do I want accepted?

- How will my readers relate to this idea or proposal? Will they benefit in any way?

- Can I construct a detailed, complete argument from this positioning?

The most common ways to frame or position a message include the following:

- Positive frame describes rewards, value, or benefits.

- Example: Farmers are "stewards of the land."

- This is a positive frame, because the selection of words conveys a positive image of farmers in relationship to the land and the environment.

- Negative frame focuses on the consequences or risks.

- Example: Agricultural production is based on "factory farming."

- This is a negative frame, because the term "factory farm" is a word choice that associates farming with a mechanized, non-natural manufacturing process.

- Fear appeals raise fear and anxiety.

- Example: Describing genetically modified food as "Frankenfood."

- This is a fear appeal because it associates a food technology with a well-known cultural icon (the "Frankenstein" novel and numerous "Frankenstein" movies) involving the creation of a monster and misuse of science.

\section{The Psychology of Persuasion}

Effective persuasion motivates people to yield to influence. Persuasion can be either pro-social, in which a person stands to gain something positive or be rewarded by agreeing, or anti-social, in which people are warned about a potential punishment or negative outcome that could happen if they do something or disagree. Public health and safety messages in the media are usually good examples of the anti-social (negative) approach to persuasion, such as:

- "Don't drink and drive."

- "This is your brain on drugs."

From a psychological standpoint, persuasion is most effective when the person doing the persuading is viewed as credible and trustworthy, and the message being conveyed is perceived to be truthful and accurate and aligned with an individual's or audience's values and interests. According to psychologist Robert Cialdini (2006), you can be more persuasive if you follow one or more of the following guidelines:

- Reciprocate: Do something for someone else. Have you ever told a friend or sibling they could borrow something of yours if they let you borrow something of theirs? When you negotiate by reciprocating, that is a form of persuasion.

- Commitment and consistency: Getting people to say they will commit to doing something is more effective than just providing them with the information they need to perform the behavior you want. An example of a commitment is a contract or petition. Being consistent is necessary if you want to establish trust. Saying one thing and doing another is not consistent, and can lead to cognitive dissonance, which is the basic incompatibility of holding two or more beliefs simultaneously. When what we believe to be true is contradicted by new information, we experience cognitive dissonance. Dissonance is not a comfortable feeling, and when it happens, we either try to ignore the new information, or we lose trust in what we have just heard or seen. Imagine believing that your best friend liked you for yourself, only to be told by someone else that your friend has been saying bad things about you behind your back. Cognitive dissonance causes you to either reconsider your friendship, or distrust the person who informed you.

- Social proof: This means that people will do what they see others doing, as long as it seems to be socially acceptable. Advertisers use social proof when they want to persuade people to buy a new product. They may run an ad showing it being used by a lot of people; therefore, it makes using the product seems like the popular thing to do.

- Liking and authority: People are perceived to be more persuasive when they are likable and perceived to be in a position of power.

In addition to these elements, effective persuasion is influenced by the believability of the person who is 
communicating, as well as by the truthfulness of the message being communicated.

\section{Summary}

Because people turn to the mass media for news and information, it is important for communication professionals and extension faculty to understand how mass media can frame messages in neutral, positive, or negative ways so they are better prepared to provide informative messages to their clients. The next publication in this series focuses on how to create persuasive essays, speeches, and communications campaigns.

\section{References}

Cialdini, R. (2006). Influence: The psychology of persuasion. New York, NY: Harper Business.

Telg, R.W. \& Irani, T.A. (2012). Agricultural communications in action: A hands-on approach. Delmar Cengage Learning: Clifton Park, NY. 